\title{
ENRIQUE LIHN, CUENTISTA
}

\author{
POR \\ Miguel GoMes \\ University of Connecticut
}

I

Existe una fábula, amarga para muchos escritores, en la que un autor que se ocupa de varios géneros a la vez acaba confundiéndolos, como si los tipos literarios pudieran "contaminarse" entre sí. No me refiero, desde luego, al diálogo comprensible, deseable y heteroglósico entre formas de escritura distintas, sino al lugar común crítico que en ciertas ocasiones ha pretendido hacer pasar a Alfonso Reyes por "un ensayista que escribió cuentos y poemas" o a Oswald de Andrade por "un novelista de vacaciones en la poesía". Ambas figuras, claves en las letras latinoamericanas, constituyen un buen ejemplo de este fenómeno de recepción, pues la calidad de sus aportaciones en diferentes modalidades literarias es innegable: los cuentos de Reyes, para no ir muy lejos, podrían sorprender por sus audacias experimentales a un lector del Boom; los poemas de Andrade por su parte, se adelantan en muchos aspectos al frenesí conscientemente intertextualista de la lírica de fines del siglo $\mathrm{XX}$.

El caso del chileno Enrique Lihn, para muchos críticos, ha sido el del poeta dedicado pasajera, excéntricamente, a la narrativa y a otras actividades artísticas o para-artísticas menos tradicionales, como el happening o el comic. La prolífica e importante producción poética de Lihn, por supuesto, explica la poca atención que se ha prestado a sus cuentos, novelas o piezas dramáticas. El propósito de estas líneas es efectuar una lectura del cuentista como entidad en principio independiente de otras vinculables al autor. Quizá esto se interprete como acto de justicia; preferiría, en cambio, sin menoscabo de lo anterior, concebirlo también como ejercicio de sentido común critico.

No fue Lihn un cuentista de paso. Ni siquiera es posible achacarle ingenuidad de aficionado en lo que respecta a sus teorías del oficio. Un breve pasaje de las Conversaciones con Enrique Lihn de Pedro Lastra - uno de sus estudiosos más consecuentes- podría dejar en claro la precisión de los modelos narrativos que siguen las dos compilaciones de cuentos de nuestro autor, Agua de arroz (1964) y La República Independiente de Miranda (1989): 
Tú te acuerdas de esta proposición de Roland Barthes, que resume muchas páginas del análisis estructural del relato: "Quien habla (en el relato) no es quien escribe (en la vida) y quien escribe no es quien existe". Me acojo a esta proposición. Dejemos de lado al hablante, que suele no ser más que un personaje del texto: pensemos en el que escribe. Éste, como sujeto de la enunciación, es sólo una presencia indirecta respecto de la cual la escritura se comporta como un rastro. Tú puedes percibir esta ausencia integrando esas señales. ... Este sujeto, que no es el autor real (el que existe), es textual, aunque no se encuentre directamente presente en la escritura. Este sujeto textual es quien se encuentra más cercano del autor real y se nutre de él, pero no lo desdobla, no es un reflejo. ${ }^{1}$

El primer abismo que se instala entre cuento y poema en la obra de Lihn surge tal vez de este reconocimiento, complementado, de inmediato, por otro:

Pero al mismo tiempo yo creo que en cierto tipo de poesía ... el sujeto textual ha sido experimentado por el autor real como su doble: el autor no simula $\longrightarrow$ o cree que simulala voz de un personaje sino que habla a título personal. ... Yo me reconozco en el sujeto de poemas como "La pieza oscura": declaro esa referencialidad. Pero hay que atender a este dato: ese sujeto es quien escribe y no el sujeto existencial al cual se refiere el que escribe. El sujeto que escribe debería tener siempre conciencia de que es literatura ...

Desde luego que puede hacerse un reparo: el sujeto que conversa con Pedro Lastra no es el que escribió La pieza oscura ni el que escribiría novelas o relatos breves; por tanto, las observaciones de aquél no son pertinentes para el análisis de las páginas de éstos. Por tal sendero ontológico, no obstante, llegaríamos a la conclusión abrumadora e inútil -nihilista, acaso- de que nadie es nadie. No nos ceñiremos aquí a reducciones semejantes. Más bien, nos esforzaremos en percibir la presencia prototextual de un Lihn teórico que se despliega en las Conversaciones como en pocas otras oportunidades. Dentro del campo magnético de las "obras completas", esa voz meditativa contribuye a plantear cierta manera de recibir lo escrito en la que el lector vincula textos entre sí gracias al nombre "Enrique Lihn" - factor que la crítica formalista tendía a obviar, en detrimento del universo denso de la intertextualidad "refleja". ${ }^{2}$ En otras palabras: las Conversaciones, por su carácter de summa expositiva, constituyen un margen - prólogo, epígrafe, nota a pie de página o epílogo - de la labor restante del autor y han de leerse necesariamente vinculadas a la literatura lihneana, en la misma medida que el Borges o el Neruda biográficos son también textos que deben tomar en cuenta los investigadores y comentaristas para entender ciertas respuestas del público de la época o ciertos elementos del dinamismo interno de la escritura.

El Lihn teórico de sí mismo - uno de "los que escriben"- ha propuesto una fórmula de los géneros que trataremos de someter a prueba a continuación.

La pieza oscura, ciertamente, pero también otros poemarios que lo siguieron son susceptibles de revisiones en las que el escritor-hombre intervendría. Y no hay razón para

\footnotetext{
${ }^{1}$ Pedro Lastra, Conversaciones con Enrique Lihn (Santiago de Chile: Atelier Ediciones, 1990) 106.

2 Véase Pedro Lastra, Relecturas hispanoamericanas (Santiago de Chile: Editorial Universitaria, 1986) 48.
} 
fruncir el ceño estructuralista: si damos a la pluralidad de lecturas posibles de un texto su sitial entre los objetos de estudio crítico, una interpretación "biográfica", "psicológica", "personal", es tan importante y válida como cualquier otra. La imagen que del autor se forma el lector es también un signo y aporta significados. Un ejemplo claro: leer Diario de muerte teniendo en cuenta que fue escrito por Lihn casi en su lecho de moribundo es un factor imprescindible a la hora de intentar discernir el papel de lo fragmentario en el libro, en el que la brevedad epigramática y el silencio agónico poco a poco se consustancian la parquedad y La Parca se encuentran en la escritura literaria y en la otra escritura, la vital, a la que accedemos a través de las notas de los editores de la obra póstuma. ${ }^{3}$ Sobre el protagonismo del personaje autorial en la lírica lihneana ya la crítica ha hecho observaciones certeras en las que no creo necesario insistir. ${ }^{4}$

En lo que se refiere a la narrativa, por el contrario, poquísimo se ha dicho hasta el momento. Contamos con la mención de una "ausencia" en Conversaciones y, en esta misma fuente, con la preciosa observación de Lastra acerca de un distanciamiento entre el sujeto textual y el extratextual notorio en los títulos no líricos de Lihn. ${ }^{5}$

Empecemos, tentativamente, por buscar en las técnicas de enunciación una primera esfera donde pueden verificarse tales supresiones, carencias o alejamientos en el interior de la subjetividad hablante. Un estudio de Óscar Hahn sobre "Huacho y Pochocha", cuento de Agua de arroz, será clave para nosotros. Lo que Hahn denomina, a contrapelo de Barthes, "efectos de irrealidad" en el texto consiste en el conjunto de estrategias por las que el narrador nos obliga a recordar que, al adentrarnos en su discurso no vivimos la vida, sino que leemos literatura. ${ }^{6}$ Una primera persona del singular dice haber visto en un muro un par de nombres encerrados en un corazón. A partir de este momento, la empresa narrativa se transforma en la reconstrucción imaginaria de una historia de amor adecuada a ese vestigio gráfico. Se esbozan distintas Pochochas y distintos Huachos hipotéticos, personajes en busca de nombre y acontecimientos propios, pero su fantasmalidad, su irrealidad, se acentúa al contrastar con la exactitud con que se pinta a sí misma la voz que narra esta aventura plenamente verbal. En palabras de Hahn, "el hecho de que el narrador se presente como un escritor profesional determina por completo la estructura del cuento ... porque al mismo tiempo que una historia de amor, 'Huacho y Pochocha' es la relación de cómo se va construyendo esa historia. No hay, por lo tanto, ni reflexiones sobre la escritura en abstracto, ni se muestra el producto, retirado ya el andamiaje". ${ }^{7}$

Ahora bien, ¿es el narrador el demiurgo absoluto de los múltiples Huachos y Pochochas que conocemos? De ser esto cierto, los efectos de irrealidad lúcidamente apuntados por Hahn desembocarían en un nuevo realismo: el de los procesos de creación literaria puestos

\footnotetext{
${ }^{3}$ Enrique Lihn, Diario de muerte. Pedro Lastra y Adriana Valdés, editores (Santiago de Chile: Editorial Universitaria 1989) 11-2 y 83-4.

${ }^{4}$ Véase Jaime Giordano, Dioses, Antidioses ... (Concepción Chile: Ediciones Lar, 1987) 316.

${ }^{5}$ Giordano, Dioses 105.

${ }^{6}$ Óscar Hahn, "Los efectos de irrealidad en un cuento de Enrique Lihn", Mario A. Rojas y Roberto Hozven, editores, Pedro Lastra o la erudición compartida: estudios de literatura dedicados a Pedro Lastra (México: Premià Editora, 1988) 259.

${ }^{7}$ Hahn, "Los efectos ..." 259-60.
} 
en escena; el narrador habitaría un espacio "real" en contraste con sus personajes, seres de ficción. Obviamente, la situación no resulta tan sencilla en el cuento de Lihn y Hahn ya nos ha prevenido al respecto. Por nuestra parte, pensemos en que constantemente quien fabula extrae datos de su experiencia personal para rehacer los hechos de los dos nombrespersonajes ("Oí hablar de un tipo que envejeció"; "de ese efimero amigo obtuve una información"; "A Pochocha, en cambio, suelo estar seguro de contarla en la lista de mis conocidos" $)$. Los traspasos entre los dos planos mencionados, el del narrador y el de la ficción son frecuentes y perfilan un orbe ambiguo, de fronteras vaporosas. El testigo se ha topado con muchos Huachos y Pochochas y convive con ellos, participando, por lo tanto, de la identidad movediza de dichos prójimos; es decir, se textualiza a sí tanto como a los individuos que le han servido de fuente de información o inspiración. Se hace transparente el sujeto; a nuestra vista se confunde con lo que nos propone como invención.

La pieza con que se cierra Agua de arroz puede analizarse desde una perspectiva semejante. Luego de cuentos acerca de nombres sin personaje y de personajes sin nombre —a "Huacho ..." se añaden "Agua de arroz" y "Estudio" - en el "Retrato de un poeta popular" adquiere gran importancia el problema de la caracterización del hablante en primera persona que se pinta a sí mismo, con todo lo que esto significa: una fijación, un intento de dar objetividad a una subjetividad. Notemos, pese a ello, las paradojas enunciativas que supone la narración de un individuo por definición confundido con el pueblo, con una multitud en la que se siente a gusto, sea ésta nacional o de clase ("si algo le censuro yo a mi gente, en general es la falta de ojo para visualizar la realidad que nos tiene a todos jodidos"), sea ésta de oficio ("en cuanto a mí, todos los poetas tenemos su orgullo de serlo, lindante en la vanidad"10). Como se advertirá, el "yo" que se dirige a los poetas cultos - "ustedes", desde el principio del relato- fácilmente y aprovechando cualquier oportunidad, se reintegra a un "nosotros suscitando dudas sobre los límites existenciales del que cuenta. Para colmo, una nueva media luz se producirá cuando se nos revele una ruta diferente para la despersonalización o la metamorfosis del hablante:

Y le pego también a lo que es discurso u oratoria o lo que sea conforme a la ocasión. Son las palabras en general, mi amigo. Ustedes como poetas cultos quizá me entiendan. De repente, zas, ahí está uno, el calladito, dale que dale hablando por el campeonato, fundiéndose con el lenguaje. ${ }^{11}$

Al igual que el narrador de "Huacho y Pochocha", el del "Retrato ..." se convierte a sí mismo en literatura, confiesa su esencia lingüística. Habría que añadir a esto el hecho de que el nudo de su relato, el enfrentamiento con el marido de una mujer por la que se siente atraído es un fenómeno especular. El contrincante sexual es también "payador poeta popular" $\mathrm{y}$, aunque risible en su aspecto, hay una conciliación puesta en términos de respeto, todo el lance probable de seducción y adulterio se resuelve y detiene con un gesto cortés:

\footnotetext{
${ }^{8}$ Enrique Lihn, Agua de arroz (Buenos Aires: Centro Editor de América Latina, 1968) 24, 27 y 28 , respectivamente.

9 Lihn, Agua ... 83.

${ }^{10}$ Lihn, Agua ... 93.

"Lihn, Agua ... 71.
} 
A lo caballero. Me dirigí al hombre pidiéndole autoridad para sacarla. Y bailamos ... guardando entre ella y yo las distancias de salón.

No habíamos cruzado una palabra en toda la noche. ¡Y que nunca lo hiciéramos! ... Cuando me volví a sentar, fue como si me recogieran todo mojado en un buque extranjero... Pero estaba salvado. ${ }^{12}$

La salvación consiste, en cierta forma, en abstención: evitar la disputa implica un retorno a la fraternidad con un compañero de oficio y, por consiguiente, una recuperación de sí, pero entendida como reencuentro con la poesía:

No iba a volver al galponcito, claro, que me traía voces de fiesta por el aire ... En el espíritu volví y ahora había una fiesta grande para el mundo. Y nada que pudiera agriarla, ni yo mismo. Ni la mujer alzada, ni el marido paciente y sufriente ... Nada. La pura poesía fue la que vi en todo, como si el mundo se aligerara de un sueño pesado. ${ }^{13}$

La subjetividad inscrita en el texto se autorretrata como criatura literaria y renuncia a toda independencia ontológica respecto del "oficio".

La primera pieza de La República Independiente de Miranda resulta en extremo afín tanto a "Huacho y Pochocha" como al "Retrato ...". "Los gatos" se presenta como una descripción fríamente científica de los felinos domésticos de Manhattan, con interesantes agregados sobre sus colegas del Tercer Mundo. La impersonalidad inicial pronto se trastornará cuando descubramos un "yo" que se caracteriza como "hispánico" y dueño de una agencia especializada en castrar gatos. Curiosamente, las costumbres de las mascotas y las de los amos irán aproximándose más y más hasta llegar a un trasvase obvio hacia la mitad del "informe":

Yo, por ejemplo, y mis siete mujeres sucesivas - los latinos somos monógamos por naturaleza - trabajamos en mi firma en paz y armonía ... También a mi gato le di en su juventud el gusto de la variedad en materia de gustos. Lo casé siete veces con distintas gatas del distrito en lo que fue un sondeo profundo a los prejuicios hispánicos que luego he conseguido vencer en mí y en los demás. ${ }^{14}$

El que estudia se identifica con lo estudiado lo que lo convierte en objeto de su propio discurso; un nuevo "autorretrato", esta vez metafórico. La capacidad de transpersonalizarse del hablante viene cifrada, en esta oportunidad, no en la colectivización del "yo", como en el monólogo del poeta popular, ni en la convivencia del narrador con los seres que intenta ficcionalizar, como en el pseudotestimonio de la vida de Huacho y Pochocha; sino, más bien, en una figura retórica constante: la enálage. El dueño de la agencia, aprovechándose del nombre de ésta, "Maldonado Center", se refiere a sí mismo con gran persistencia en tercera persona: "Maldonado cumple" "Maldonado se hizo allí de su primera clientela";

\footnotetext{
${ }^{12}$ Lihn, Agua ... 96-7.

${ }^{13}$ Lihn, Agua ... 97.

${ }^{14}$ Enrique Lihn, La República Independiente de Miranda (Buenos Aires: Editorial Sudamericana, 1989) 20-1.
} 
“¿son éstos los últimos años de mi vida? Maldonado no es inmortal". ${ }^{15}$ El resultado no es otro que una reafirmación de la unidad de sujeto y objeto que verbaliza aún más a la voz narrativa y le resta vida "externa", vida que el lector real pueda desgajar de la escritura.

\section{IV}

Hemos tratado algunos casos en los que la enunciación confirma, en los dos libros de cuento de Enrique Lihn la presencia de una "ausencia": la condición de lenguaje de los hablantes es un obstáculo que nos impide asociarlos con el sujeto que escribe en la realidad. Veamos ahora si algo semejante podría verificarse en la esfera del enunciado. Pasemos permítaseme la distinción, no siempre válida - del que dice a lo dicho.

La narración que da título a Agua de arroz versa, en gran medida, sobre la alienación. He aludido antes a esto al hablar de personajes sin nombre en el volumen. Sabemos que el protagonista se ha separado de su mujer - que recibe un nombre poco inocente: Normay debe quedarse en casa, cuidando a la niña de ambos, mientras la madre sale "a quién sabe qué". En soledad, acompañado sólo por la recién nacida, cuyo sueño es "profundo" y "minucioso", el padre percibe el nacimiento de otro ser de formas indefinibles. Primero, el alumbramiento adquiere la apariencia de un desdoblamiento:

Se sentía su propio detective privado en plena actividad vergonzante. Dos personas en una. Eficacia probada. Pero el total de su envilecimiento era mayor que la suma de sus partes. ${ }^{16}$

Luego, a raíz de la sensación prematura de vileza, el doble se ensombrece progresivamente:

La nifia no lo iba a reconocer con seguridad, pero acaso podía ... ver en él nada más que el vacío opaco, nebuloso concentrándose en torno suyo, amenazante quizá, como todo lo indeterminado o el remedo usurpador de otra persona; la verdadera. ${ }^{17}$

La presencia extraña es llamada, unas veces, "ello", caos, efervescencia, "barro mismo incorporándose lúcidamente [...], sin edad, ni sexo, ni condición, ni nada"; otras veces, se habla sin rodeos del "monstruo adentro", noción que persistirá hasta las últimas líneas. Lo que cuenta, sin embargo, es la ambigüedad a que se prestan estas descripciones, pues entre las expectativas del lector han de señalarse, al menos, dos interpretaciones del relato: una fantástica o semifantástica y otra psicológica. El monstruo del que el padre debe proteger a la pequeña pese a propiciar en algunos momentos una atmósfera alucinante, no tarda en manifestarse como monstruo real, o sea, un engendro de la psique. Un junguiano, con razón, vería en la aparición violenta de ese "enemigo" oscuro una figuración de la "sombra" en un hombre que empieza a sospechar que es mal padre, que ha perdido toda "norma" e

\footnotetext{
${ }^{15}$ Lihn, La República ... 21, 23 y 27.

${ }^{16}$ Lihn, La República ... 5.

${ }^{17}$ Lihn, La República ... 9.
} 
intuye, además los abismos a los que el alcoholismo lo ha arrojado. En todo caso, el descubrimiento de la duplicidad, de la simultaneidad de presencia y ausencia, propicia el desenlace: el hombre, al borde de la demencia, cae en la cama que ya no es suya e intenta "desbaratar a golpes" al otro, nada más que un apelotonamiento de sábanas y vacío. Llora, finalmente, y entiende que el suyo es "caso perdido". El proceso de hacerse ajeno es irreversible.

Uno de los textos recogidos en La República ..., no obstante, puede ser mucho más ilustrativo acerca de la pasión lihneana por las disociaciones. Se trata de "Para Eva", que comparte con "Agua de arroz" no sólo conflictos entre hombres y mujeres, sino el poder sugestivo de los nombres propios. Eva, al principio, es una generalidad nominal: "Eva de Perón, Ave Eva Dalí, Eva Braun (María) y otras". Después, pasa a ser Eva Montes de Ramírez, amor imposible de Alcides Lima, artista que, ante las dificultades vagas de una cercanía erótica real —el personaje femenino resulta tan inasible como su nombre- decide "copiar" a la mujer inalcanzable. El narrador, amigo de Lima, nos explica así el proyecto:

Quería ser Eva y prohibírselo a la vez. A eso le llamaba pensarla. Sólo muy lentamente algunos sospecharon años después que ese matrimonio se había consumado a su modo. Únicamente yo supe de esa unión conyugal abstracta que pretendía ser, según Alcides, un triunfo de la voluntad ...18

La noche que Lima revela a su confidente la empresa descabellada está vestido con el traje de Eva Montes, por lo que es confundido con un "vulgar travesti". Acto seguido, el narrador corrige su primera impresión y compara el gesto con una performance, "acciones de arte que tendrán lugar un cuarto de siglo más tarde". Las ocurrencias de Alcides, en efecto, serán tildadas de body-art, lo que bien podría inducirnos a realizar una comparación no tan evidente: el texto corporal ajeno que desea reescribir Lima en sí mismo es similar al texto nuevo al que aspira Pierre Menard partiendo del Quijote. Aunque dispuestas en sentidos contrarios —en Lihn, el anhelo es la identidad de lo distinto; en Borges la pluralidad de lo uno- las relaciones de alteridad y afinidad en ambos casos son capaces de despertar en los lectores incertidumbres parecidas.

El andrógino mencionado por Platón podría ser la meta de Alcides Lima. Sólo que el esfuerzo de éste es desesperado desde el punto de vista de quien narra. Notemos que el testigo que teje la historia es "restaurador - algunos dicen que falsificador- de la pintura chilena" y que al pensar en su excéntrico amigo, los términos son duros:

me hubiera gustado verlo ... dedicado, en mi taller, a la restauración, la copia o el plagio de antiguos retratos, antes que perdido en Europa en la fabricación de prótesis, con su propio cuerpo, de un fantasma artificial. ${ }^{19}$

Cuando toca al narrador cumplir el último deseo de Lima, ya fallecido, el tono de los acontecimientos; de recatadamente extraño, se vuelve circense, tocado por una comicidad

\footnotetext{
${ }^{18}$ Lihn, La República ... 58-9.

${ }^{19}$ Lihn, La República ... 63.
} 
atribuible a Lihn sin el menor influjo borgiano: el albacea ha de espolvorear las cenizas del difunto sobre Eva, la de carne y hueso, aún viva, para crear un "emplasto de Adán" que es "restitución a Eva, a través del maquillaje, de esa carne que quiso ser parte de la suya, en una común consagración a la diosa del barro original; la Afrodita Barbuda". ${ }^{20}$ Pasando de la sublime idea tácita del andrógino a esta imagen freak, la perspectiva de la narración es ridiculizadora. Los sucesos pierden incluso todo carácter realista cuando leemos una advertencia ficcionalizante emparentada con las de "Huacho y Pochocha": "me corresponde ahora simular que actúo, terminando mi relato en el presente de indicativo". ${ }^{21}$ El fiel amigo se presenta ante el lecho de Eva, sorda, vieja y enferma, y decide dejar caer sobre ella lo que queda del amante. Los parientes de la mujer, en tumulto, detienen al que creen un agresor y lo arrastran fuera de la pieza. En el suelo como prueba de un fracaso, queda un reguero de cenizas: "la única señal de tu paso por la tierra, Alcides". La conclusión es más o menos obvia: el que quiso ansiosa, premeditadamente ser el otro acaba anulando su propia existencia. La ausencia de sí mismo se traduce en un salto a la nada.

En "Estudio", cuento perteneciente a Agua de arroz, los jóvenes de una escuela, cruelmente, se despojan unos a otros de su identidad a través del apodo o a través de las traiciones inesperadas a lo que parecían buenas amistades. En "Entre Caín y Abel", de La República ..., un antillano en Nueva York confunde su existencia cotidiana con la de personajes bíblicos ... Como vemos, el hecho de que ciertos personajes pierdan una y otra vez su esencia o descubran que ésta, en realidad, es engañosa, podría en cierta forma ser un reflejo en el plano del enunciado de lo que ya habíamos visto en la enunciación. Toda representación de la subjetividad humana para el Lihn cuentista resulta dudosa.

Y no hay, como se sabe, subjetividad verbal que prescinda de una definición del tiempo y el espacio en los que se sitúa. Si nos interrogamos sobre la plasmación de éstos en los textos que releemos, daremos con recursos muy parecidos a los empleados por el escritor en la concepción de la voz narrativa y de los personajes.

Particularmente, La República ... insiste en la fabulación geográfica e histórica de lo fantasmagórico. Ya en "Los gatos", Maldonado teme la existencia de la "gatopía", "lugar que no hay" y que "trae mala suerte mirar". "Los secos y los húmedos", "Panorama artístico de la República Independiente de Miranda", "Lagarto Islote" y "Teoría del matrimonio", incluidos en el mismo libro, se dedican a recrear a profundidad o a confirmar la singularidad de Miranda, país indefinido que figuraba antes en La orquesta de cristal, novela publicada por Lihn en 1980. Vago eco del Buñuel de El discreto encanto de la burguesía, Miranda se caracteriza por una "vacuidad existencial"22 que la transforma en una utopía en el sentido etimológico estricto: no hay tal lugar. Puesto que en "Panorama ..." se nos advierte que ese espacio contiene una naturaleza y un hombre geométricos, no es infundado prever que avanza hacia la abstracción como lo hizo la pintura del siglo XX:

\footnotetext{
${ }^{20}$ Lihn, La República ... 56.

${ }^{21}$ Lihn, La República ... 64.

${ }^{22}$ Lastra, Conversaciones 114.
} 
Hay zonas cubistas del territorio de Miranda, saldos de una geografía periclitada, donde para vivir con tranquilidad bajo árboles cilíndricos o sobre lomas esféricas o cónicas hay que participar por emanación de esas formas ... Hay ancianos que viven abstraídos en el cubismo durmiendo en cabañas muy simples y alimentándose de los frutos de la tierra. Flores y frutos parecen artificiales, dadas sus formas y colores. Agréguese a ello una rara renuencia a descomponerse y su condición inodora e insípida ... Todavía se ve entre nosotros personas de rasgos excesivamente regulares.

El protector general tiene, desde luego, una marcada prestancia estatuaria ...23

El narrador o informante participa de esa textualización artística del mundo que describe, y confiesa su índole aséptica y, sobre todo, su falta de consistencia como individuo:

De más está decir que nuestro punto de vista en el presente trabajo tiende más a la descripción desapasionada que a la valoración efervescente ... Si las obras provienen de las obras en una historia que podría prescindir del nombre de los autores, resulta por lo menos patético que ellos se desvivan por actualizar esa virtualidad que los arroja al anonimato.

La impersonalidad, en fin, se soporta con un poco de gloria. ${ }^{24}$

"Historia", cuyo referente es la literatura y, por ende historia cercana a la ficción. "Lugar", que reproduce visiones plásticas y ámbitos imaginarios, lo que es igual a una reproducción de reproducciones. "Voz", que intenta restar individualidad a su presencia ... El "Panorama ..." suma los rasgos dominantes de los cuentos de Lihn y puede considerarse como una de las piezas más representativas de su narrativa breve.

Recordaba al principio de estas notas la imagen disparatada del poeta narrador, el narrador ensayista, el ensayista poeta y otras variantes de una quimera engendrada por la falta febril de imaginación de algunos críticos. Creo que ahora es posible afirmar, así sea discretamente que Lihn como escritor no asume ninguna de estas formas mitológicas y monstruosas.

Entre sus poemas y sus cuentos al menos, hay una diferencia expresiva clara; una cosmovisión distinta llega incluso a separarlos. Como narrador, le debemos fábulas en las que la vacuidad y los espejismos existenciales juegan papel de primer orden; le debemos una pasión por la nada y su hermana gemela, la verbalidad a solas casi opuesta a ese complejo mundo individualizable que constituye su lírica: parte ésta de una prehistoria o caos -Nada se escurre (1949), Poemas de este tiempo y de otro (1955); consiente entonces una revisión de los orígenes y la infancia - La pieza oscura (1963); inmediatamente, una peregrinación; un viaje de búsqueda - Poesía de paso (1966), A partir de Manhattan (1979), Pena de extrañamiento (1986), para sólo nombrar tres títulos de una lista muchísimo más extensa; y con una lógica biográfica sorprendente propone un cierre escatológico de

\footnotetext{
${ }^{23}$ Lihn, La República ... 78-9.

${ }^{24}$ Lihn, La República ... 90-1.
} 
gran intensidad -Diario de muerte (1989). Si por una parte el poeta se ha forjado una máscara laboriosa intrincada, por otra, la ausencia o evanescencia de la persona y sus "circunstancias" es el núcleo mismo de la teoría lihneana del cuento que hemos entrevisto en estas páginas.

Tanto Agua de arroz como La República ... recogen relatos de un narrador "puro" que se precia de serlo al punto, de borrar afanosamente lo que para sus lectores podrían ser huellas del narrador "hombre". Baste la eficacia del artificio para iluminar una vez más, la innegable diversidad de dotes creadoras de Enrique Lihn. 